\title{
Um guia de construção de Posters para estudantes
}

\author{
(A student guide for designing poster presentations)
}

\author{
Autores: Manuel J oão Costa \\ Afiliação:Universidade dos Açores, Departamento de Ciências Tecnológicas e Desenvolvimento \\ mmcosta@notes.uac.pt
}

Posters are probably the means of communicating information used most frequently by young scientists. In this work, a guide for building better posters is presented: It provides students with objective information and practical suggestions that may facilitate poster design an improve quality and impact. In my experience, students generally appreciate the contribution of the guide.

\section{NTRODUÇÃO}

A apresentação de um poster, constitui freqüentemente a forma segundo a qual os jovens divulgam os seus primeiros resultados científicos. Para ser bem sucedida, os recém-licenciados em áreas científicas devem dominar a preparação de trabalhos neste formato. Por conseguinte, não é surpreendente que a construção de posters tenha vindo a ser adoptada como método de trabalho no âmbito de diferentes Disciplinas, em alternativa a formas mais usuais, como por exemplo a escrita de relatórios.

A construção de posters é muitas vezes transmitida aos estudantes como um processo essencialmente intuitivo. Porém, à semelhança doutros tipos de trabalho (como a escrita de relatórios ou a planificação de ensaios experimentais), a preparação de posters com qualidade obedece a critérios definidos e apela a competências particulares. Por exemplo, o seu carácter esquemático exige uma síntese da informação em períodos obrigatoriamente curtos, objectivos e pertinentes e que devem surgir integrados no trabalho final, de forma cientifica e graficamente coerentes. Implícito a um poster de sucesso, está também o uso de competências do foro não científico, como a capacidade de tornar o "produto final" apelativo e o saber tirar partido de softwares apropriados. Os posters sobre abordagens biomoleculares não são excepção.

Alguns critérios implícitos ao método de construção de posters podem encontrar-se em livros (Briscoe 1996, Malmfors et al. 2000, Valiela 2001), artigos publicados em revistas de ensino de áreas da especialidade (Brown 1997) e guias online, que vão desde as descrições mais exaustivas sobre o poster e as etapas da sua construção (Radell 1999) até à sistematização de elementos chave (U.S Department of energy 1998) e aos guias para a aplicação de software (Health Services - University of Washington ). Uma vez que estes materiais se encontram predominantemente escritos em inglês - uma pesquisa na internet (Setembro de 2001) resultou apenas num "hit" em Português (IC-online 1997) - tenho observado que a sua consulta constitui um problema para alunos com domínio rudimentar desse idioma (estes constituem uma percentagem apreciável dos alunos de Licenciaturas em que tenho lecionado).

Os motivos expostos anteriormente motivaram-me para esboçar um ?Guia prático para a concepção e elaboração de posters?, que incluo seguidamente. O guia é fornecido aos alunos de aulas práticas no âmbito de disciplinas de Bioquímica de duas licenciaturas da Universidade dos Açores, como material de apoio para a produção de um destacável de um poster. 
dum poster com sucesso. Não se pretende que o mesmo seja tão exaustivo quanto alguma bibliografia incluida. Em depoimentos recolhidos, verifica-se que a utilidade do guia é apreciada. Além disso, tem-se vindo a observar que os mesmos alunos constroem posters de qualidade em disciplinas que frequentam posteriormente.

\title{
Guia prático para a concepção e elaboração de posters
}

\author{
"...posters are an established method of reporting scientific findings..."
}

Bernard Brow n (1997)

A maioria dos cientistas apresenta os seus primeiros resultados em trabalhos sob a forma de Posters. 0 respeitar dum conjunto de regras na sua construção, contribui positivamente para o sucesso dum poster.

\section{Os posters em congressos: exposição e análise}

As sessões de exposição de Posters são geralmente bastante movimentadas (principalmente nas horas de coffee break). Estas têm a duração de um dia (ou parte), e incluem geralmente dezenas de trabalhos (em Congressos de maiores dimensões esse número pode atingir as centenas) expostos simultaneamente. Os posters são afixados em Placards, onde ficam à disposição da Comunidade Científica, que os analisa na maior parte das ocasiões sem os autores estarem presentes. Por conseguinte, os posters devem "falar por si".

A consulta de posters é feita de pé, pelo que constitui um exercício extremamente cansativo. Por esse motivo, os posters têm que competir entre si pela conquista da atenção da audiência. É vital que os autores invistam fortemente na captação do interesse de leitores - entre eles, potenciais colaboradores, orientadores ou empregadores futuros - sob o risco de os mesmos passarem desinteressadamente pelo poster.

As comissões organizadoras dos Congressos estipulam um período durante o qual um dos autores deve estar presente junto do painel. Esse período é fundamental pois permite a troca de impressões com a comunidade científica presente no Congresso. Não raramente, são estabelecidos contactos e colaborações preciosas.

\section{Princípos gerais para o sucesso dum poster}

À semelhança de qualquer cartaz publicitário, os posters devem ser sintéticos e apelativos. A informação apresentada deverá ser retida facilmente, pelo que deve ser perfeitamente sistematizada. Um poster será mais apetecível se:

- os pontos chave do poster forem evidentes a $\mathbf{2 m}$ de distância

- o poster for visualmente apelativo, tiver uma concepção agradável e/ou inovadora;

- o número de palavras não for abusivo (máximo de 200 em texto corrido);

- a leitura for fácil e intuitiva;

- o leitor precisar de pouco tempo - 2 minutos - para perceber o trabalho.

\section{DEI A CHAVE: O MUI TO É I NI MI GO DO BOM !!!!}

\section{Alguns detalhes e algumas máximas}

\subsection{Preparação}

- "Nunca é cedo demais para pensar no poster" (1). A concepção do poster começa no momento em que surge a pergunta/o problema a esclarecer. Já devia ter começado a pensar no assunto!

- O enunciar do problema da forma mais clara e sucinta é um excelente primeiro passo. Enunciei claramente o problema?

- Uma pesquisa sistematizada é um contributo importante para o sucesso da preparação do poster. Definir áreas chave! 
- As linhas e/ou etapas sistematizadas para a pesquisa da informação podem constituir secções do Poster. Manter um ficheiro de ideias.

-Durante a pesquisa, devem ser recolhidas imagens o mais apelativas e elucidativas possível: Uma imagem pode valer 1000 palavras.

- Desde o início, deverão ser produzidos esboços da organização do poster em folhas de papel, pois tal ajuda à estruturação progressiva do trabalho . Realizar estudos escritos!

\subsection{Organização no papel}

-A informação deve ser simples de ler e compreender: O leitor tem pouco tempo.

- São 3 os itens a trabalhar: espaço livre, texto e imagens. Estes devem aparecer equilibrados, o que geralmente envolve 1 de 2 opções: a) 1/3 para cada,; b) $50 \%$ de texto e $50 \%$ de imagens. Não favoreci um componente?

ATENÇÃO: Frequentemente, priveligia-se o texto o que desencoraja o leitor - imagine-se a ler em pé dezenas de trabalhos assim!...

- Dados numerosos devem ser sistematizados em Gráficos ou sob a forma de Tabelas ou desenhos ilustrativos. As tendências é que importam!

\subsection{Sequência da informação no formato final}

- A mesma de uma leitura normal, geralmente do topo esquerdo até ao fundo direito. $\mathbf{O}$ pescoço do leitor é importante!

- Numerar, usar setas ou cores indicativas, ajuda a orientar o leitor. Não posso torná-lo menos confuso?

\subsection{Formato do texto}

- Deve poder ser lido perfeitamente a $\mathbf{2 m}$ de distância. $\mathbf{O}$ tamanho das letras é suficiente?

- Parágrafos de texto apenas em maiúsculas são difíceis de ler.

- A leitura é facilitada quando o espaçamento de texto é de linha única e o dos parágrafos de linha dupla.

Mudar o espaçamento facilita a leitura?

- As frases longas desanimam. Curto e directo s.f.f.!

- Sugestões: para tamanhos de letra para o formato A4: título: 20 pt; cabeçalhos: 10 pt; texto: 5 pt. Alterando o tamanho da letra a informação fica melhor sistematizada?

\subsection{Raciocínios}

- trabalho realizado deve ser compreendido mesmo na ausência do autor. O Poster "fala por si"?

- As etapas de raciocínios efectuados podem corresponder a secções do poster, na mesma sequência.

Encadear logicamente.

- A leitura do Resumo e da Conclusão deve desafiar o leitor a percorrer o resto do trabalho. Posso expor as conclusões de forma mais interessante?

\section{O "Handout": uma ferramenta útil de trabalho e de divulgação}


resultante, é preparar o poster em computador, e imprimi-lo numa folha A4, sem alterar proporções. Esta impressão designa-se por handout do poster. Um handout confuso, de leitura difícil, sem coerência gráfica ou desproporcionado quanto às suas partes constituintes, indicia que no seu tamanho real o Poster padecerá de características semelhantes. Por outro lado, se o handout estiver bem construido, então o Poster também o estará.

Preparar handouts tem as vantagens adicionais de :

- poder ser distribuido em Congressos;

- ser facilmente arquivável

- ser uma forma mais simples e mais económica de aprender a fazer posters, do que fazê-los em tamanho de parede.

\section{AGRADECI MENTOS}

O autor gostria de agradecer ao Doutor Francisco Silva Domingues (Center of Applied Molecular Biology, Universidade de Salzburgo, Áustria) pelas sugestões fornecidas.

\section{REFERÊNCI AS BI BLI OGRÁFI CAS}

Briscoe, Mary Helen (1996). "Posters," (Chapter 9). Preparing Scientific Illustrations: A Guide to Better Posters, Presentations and Publications, 2nd ed. Springer-Verlag, New York. Pp. 131-149.

Malmfors, B.; Garnsworthy, P. \& Grossman, M. (2000). "Poster presentation". Writing and presenting scientific papers. Nottingham University Press, Nottingham. Pp103-110.

Valiela , Ivan (2001). "The poster presentation" (Chapter 9). Doing science: design analysis and communication of scientific research. Oxford University press, Oxford. Pp154-158.

Brown, Bernard S. 1997. "Poster Design: Six Points to Ponder," Biochemical Education. 25(3): 136-137.

Radel, Jeff (1999). "Designing effective posters"

http://www.kumc.edu/SAH/OTEd/jradel/Poster_Presentations/PstrStart.html (acedido a 12 de Setembro de 2001)

U.S. Department of energy (1998). "Tips for Effective Poster Presentations ";

http://www.osti.gov/em52/workshop/tips-exhibits.html (acedido a 12 de Setembro de 2001)

Health Services - University of Washington. "Creating a Poster using MS Powerpoint";

http://courses. washington.edu/ hs590a/modules/19/ppposter.html

Revista da Universidade Federal de Rio Grande do Sul (1997). "O Pôster no trabalho científico: contribuição e significados". IC-online (vol.2, no 1); http://www.ufrgs.br/revista/n1v2/produz.htm (acedido a 12 de Setembro de 2001)

Costa, Manuel J oão (2001). "Separating poster handouts into pieces to enhance student's skills". Biochemistry and Molecular Biology Education 29(3): 98-100. 